Natalie Fritz, Anna-Katharina Höpflinger, Stefanie Knauß,

Marie-Therese Mäder, Daria Pezzoli-Olgiati

Sichtbare Religion 

Natalie Fritz, Anna-Katharina Höpflinger, Stefanie Knauß, Marie-Therese Mäder, Daria Pezzoli-Olgiati

\section{Sichtbare Religion}

Eine Einführung in die Religionswissenschaft

\section{DE GRUYTER}


ISBN 978-3-11-053407-8

e-ISBN (PDF) 978-3-11-053670-6

e-ISBN (EPUB) 978-3-11-053738-3

\section{Bibliografische Information der Deutschen Nationalbibliothek}

Die Deutsche Nationalbibliothek verzeichnet diese Publikation in der Deutschen Nationalbibliografie; detaillierte bibliografische Daten sind im Internet über http://dnb.dnb.de abrufbar.

(C) 2018 Walter de Gruyter GmbH, Berlin/Boston

Druck und Bindung: $\mathrm{CPI}$ books $\mathrm{GmbH}$, Leck

www.degruyter.com 